\title{
Peran Petugas Kesehatan dalam Optimalisasi Nutrisi Ibu Hamil dan Monitoring Kesejahteraan Janin Melalui Model Edukasi Maternal-Neonatal (EMN) Berbasis Family Cultural
}

\author{
Diyan Indriyani, Sri Wahyuni
}

Fakultas Ilmu Kesehatan Universitas Muhammadiyah Jember, Jl. Karimata No. 49

Kecamatan Sumbersari, Kabupaten Jember, Jawa Timur

Email: diyanindriyani@unmuhjember.ac.id

$\begin{array}{ll}\text { Diterima tanggal } & : \text { 20 Februari } 2020 \\ \text { Direvisi tanggal } & : \text { 17 Maret } 2020 \\ \text { Dipublikasikan tanggal } & : \text { 11 Juni } 2020\end{array}$

\begin{abstract}
Abstrak
Latar Belakang dan Tujuan: Kehamilan merupakan peristiwa penting yang sangat ditunggu dalam keluarga. Keluarga sebagai pendukung utama pada ibu hamil, juga tidak terlepas dari budaya yang diyakininya. Petugas kesehatan memiliki peran dalam membantu ibu hamil dan keluarga agar adaptif dengan budaya yang dimiliki terutama dalam memenuhi kebutuhan nutrisi ibu hamil, termasuk perilaku ibu dalam monitoring kesejahteraan janin selama di rumah. Penelitian ini memiliki tujuan meningkatkan peran petugas kesehatan dalam optimalisasi nutrisi ibu hamil dan monitoring kesejahteraan janin melalui model Edukasi Maternal-Neonatal (EMN) berbasis family cultural.
\end{abstract}

Metode: Desain penelitian yang digunakan adalah pra eksperiment dengan sampel ibu hamil di RS Kalisat dan Wilayah Puskesmas Sumbersari Jember sebanyak 100 responden yang diambil secara purposive sampling. Instrument yang digunakan adalah kuesioner dan skala likert.

Hasil: Rerata peran petugas kesehatan dalam aplikasi Model EMN terhadap optimalisasi nutrisi ibu hamil pada pre test yaitu 60,51 dan hasil post test 78,30 sedangkan dalam monitoring kesejahteraan janin di rumah rerata peran petugas kesehatan pada pre test yaitu 61,50 dan nilai post test 75,65. Peran petugas kesehatan dalam optimalisasi nutrisi ibu hamil menggunakan analisis T-test didapatkan $p$-value sebesar 0,01 dan terhadap optimalisasi kemampuan ibu hamil dalam monitoring kesejahteraan janin di rumah didapatkan $p$ value 0,03 .

Simpulan dan Implikasi: Model EMN berbasis family cultural efektif terhadap peran petugas kesehatan dalam optimalisasi nutrisi ibu hamil dan monitoring kesejahteraan janin. Dengan demikian model ini dapat digunakan oleh petugas kesehatan sebagai upaya preventif terhadap kematian ibu maupun janin.

Kata Kunci: Angka kematian ibu; Budaya keluarga; Edukasi pada ibu hamil; Kesejahteraan janin; Nutrisi ibu hamil

Sitasi: Indriyani D \& Wahyuni S. (2020). Peran petugas kesehatan dalam optimalisasi nutrisi ibu hamil dan monitoring kesejahteraan janin melalui model edukasi maternal-neonatal (EMN) berbasis family cultural. The Indonesian Journal of Health Science. 12(1), 17-25

Copyright: (C) 2020 Indriyani et al. This is an open-access article distributed under the terms of the Creative Commons Attribution License, which permits unrestricted use, distribution, and reproduction in any medium, provided the original author and source are credited.

Diterbitkan Oleh: Universitas Muhammadiyah Jember

ISSN (Print): 2087-5053

ISSN (Online): 2476-9614 


\begin{abstract}
Background and Aim: Pregnancy is an important event that is highly awaited in the family. The family as the main support for pregnant women, is also inseparable from the culture he believes in. Health care workers have a role in helping pregnant women and families to be adaptive to their culture, especially in meeting the nutritional needs of pregnant women, including maternal behavior in monitoring fetal well-being while at home. This study aims to increase the role of profesional's health in optimizing nutrition of pregnant women and monitoring fetal well-being through family cultural-based Maternal-Neonatal Education model.
\end{abstract}

Methods: The research design was pre experiment with samples of pregnant women in Kalisat Hospital and Sumbersari Jember Community Health Center as many as 100 respondents taken by purposive sampling. The instrument used questionnaire and likert scale.

Result: The average role of health workers in the EMN Model application for optimizing the nutrition of pregnant women in pre-test was 60.51 and posttest results 78.30 while in monitoring fetal welfare at home the average role of health workers in pre-test was 61.50 and posttest 75,65 . The role of health workers in optimizing the nutrition of pregnant women using T-test analysis obtained a pvalue of 0.01 and on optimizing the ability of pregnant women in monitoring fetal well-being at home obtained a $p$ value of 0.03 .

Conclusion: Family cultural-based EMN model is effective on the role of health workers in optimizing the nutrition of pregnant women and monitoring fetal wellbeing. So, the model can be used by health workers as a preventive measure against maternal and fetal death.

Keywords: Family culture; Fetal well-being; Health promotion to pregnant women; Maternal death; Pregnant women nutrition

\section{PENDAHULUAN}

Kehamilan merupakan peristiwa penting bagi ibu hamil dan pasangannya. Selain kehamilan akan mengakibatkan adanya perubahan baik fisik maupun psikologis, fakta yang dihadapi ibu hamil bahwa kondisi kehamilan bisa berjalan normal maupun patologis (Indriyani, 2013). Salah satu faktor kehamilan bersifat fisiologis adalah status nutrisi ibu dalam kondisi normal. Nutrisi yang adekuat akan mendukung kesejahteraan ibu maupun janin. Hal ini karena nutrisi merupakan komponen yang sangat diperlukan untuk kesehatan ibu, sekaligus mendukung pertumbuhan janin selama kehidupan intra uterine (Indriyani, 2013).

Menurut Ketua Komite Ilmiah International Conference on Indonesia Family Planning and Reproductive Health (ICIFPRH) hingga tahun 2019 AKI Indonesia masih tetap tinggi yaitu 305 per 100.000 kelahiran hidup. Melalui Sustainable Development Goals (SDGs) target AKI adalah 70 per 100.000 kelahiran hidup pada tahun 2030 (Susiana, 2019; Fadlillah, 2019). Selain itu AKB di Indonesia juga masih tinggi dibandingkan dengan negara tetangga seperti Malaysia dan Singapura yang sudah di bawah 10 kematian per 1.000 
kelahiran bayi. Kematian bayi merupakan salah satu indikator sensitif untuk mengetahui tingkat derajat kesehatan dan kemajuan suatu negara. Tingginya kematian bayi pada usia hingga 1 tahun menunjukkan masih rendahnya kualitas sektor kesehatan di negara tersebut (Kemenkes, 2016). Untuk kondisi di Jawa Timur kematian ibu tahun 2015 mencapai 531 orangdan tahun 2016 mencapai 534 orang serta tahun 2017 mencapai 529 orang. Sedangkan angka kematian bayi di Jawa Timu tahun 2015 sebanyak 5.132 bayi, tahun 2016 sejumlah 4.870 bayi dan tahun 2017 mencapai 4.026 bayi.

Berkaitan dengan paparan tersebut di atas, data dari Dinas Kesehatan Kabupaten Jember (2018), didapatkan informasi bahwa Kabupaten Jember merupakan Kabupaten dengan AKI menduduki peringkat ketiga di Jawa Timur, dan AKB berada di peringkat kedua di Jawa Timur. Adapun kasus terbesar untuk kondisi kematian bayi (AKB), berturut-turut dari 3 tahun terakhir yaitu 2016-2018, disebabkan karena bayi lahir dengan kondisi berat badan lahir rendah (BBLR). Berdasarkan hal ini, maka perlu upaya penanganan dalam bentuk promotif dan preventif dalam bentuk edukasi kesehatan, sehingga risiko kehamilan yang berdampak pada kesehatan ibu dan janin dapat diturunkan. Agar permasalahan yang ada dapat diminalkan, maka peran petugas kesehatan sangat penting dalam mengedukasi ibu hamil termasuk keluarga, agar memiliki persepsi dan perilaku positif dalam menurunkan AKI dan AKB yang salah satunya melalui optimalisasi nutrisi ibu hamil dan monitoring kesejahteraan janin.
Hal ini karena ibu hamil dalam memenuhi kebutuhan nutrisi sangat dipengaruhi banyak faktor, antara lain peran petugas kesehatan dalam mengubah persepsi ibu hamil agar berperilaku sehat. Ibu hamil dengan malnutrisi sangat berisiko mengancam kesehatan ibu dan janin, yang berdampak pada kondisi sakit, komplikasi bahkan situasi kematian. Berkaitan dengan pemecahan permasalahan tersebut di atas, salah satunya dengan mengupayakan meningkatkan peran petugas kesehatan melalui Model Edukasi Maternal Neonatal (EMN) berbasis Family-Cultural dalam penguatan nutrisi ibu hamil dan monitoring kesejahteraan janin yang difokuskan pada ibu hamil dengan melibatkan keluarga sebagai social support, juga memperhatikan budaya (cultur) yang berkembang di lingkungan masyarakat. Masalah yang diteliti ini berkaitan dengan peran petugas kesehatan pada ibu hamil dalam optialisasi nutrisi masa kehamilan dan monitoring kesejahteraan janin

\section{METODE PENELITIAN}

Design penelitian ini PraExperiment Pre-Posttest Design. Teknik pengumpulan data menggunakan aplikasi Model MEP berbasis Family Cultural sebagai suatu intervensi, kuesioner dan skala likert. Selain itu penelitian ini juga telah lolos uji etik dengan No.321/KEPK/FIKES/III/2020.

Jumlah sampel yang digunakan yaitu 100 ibu hamil di Rumah Sakit Kalisat dan Wilayah Puskesmas Sumbersari Jember dengan tehnik Purposive Sampling yang dimulai pada bulan Maret-Mei 2020 Analisis data menggunakan Dependet T-test. 


\section{HASIL}

Kegiatan penelitian ini difokuskan pada peran petugas kesehatan yang ada di Rumah Sakit Kalisat dan Puskesmas Sumbersari Jember. Melalui penelitian petugas kesehatan melakukan penerapan Model EMN berbasis family kultural pada langkah pemberian edukasi dengan topik nutrisi ibu hamil dan cara monitoring kesejahteraan janin selama ibu hamil di rumah. Edukasi yang telah dilakukan oleh petugas kesehatan dinilai keberhasilannya melalui perubahan persepsi dan kemampuan ibu hamil tentang pengelolaan nutrisi masa kehamilan dan cara melakukan monitoring kesejahteraan janin selama di rumah. Peneliti sebelumnya melakukan pengukuran awal (pretest), yang dilanjutkan dengan aplikasi Model EMN berbasis Family Cultural, kemudian mengukur kembali setelah intervensi (postest). Metode intervensi menggunakan tehnik ceramah, tanya jawab dan demonstrasi.

Karakteristik responden diketahui bahwa usia ibu hamil sebagian besar adalah 20-35 tahun yaitu 71 responden (71\%), status paritas jumlah terbanyak multigravida yaitu 59 responden (59\%), tingkat pendidikan terbanyak adalah SMA, sebagian besar ibu bekerja yaitu 61 responden (61\%) dan hampir seluruhnya memiliki riwayat ANC teratur sejumlah 88 responden $(88 \%)$ (Tabel 1).

Peran petugas kesehatan dalam optimalisasi nutrisi ibu hamil dengan pendekatan Model Edukasi Maternal Neonatal (EMN) Berbasis Family-Cultural didapatkan $p$ value 0,01. Hal ini berarti Model EMN berbasis Family Cultural efektif terhadap peran petugas kesehatan dalam optimalisasi nutrisi ibu hamil (Tabel 2). Begitu pula peran petugas kesehatan dalam optimalisasi monitoring kesejahteraan janin di rumah dengan pendekatan Model Edukasi Maternal Neonatal (EMN) Berbasis Family-Cultural didapatkan $p$ value 0,03. Berdasarkan hal tersebut maka Model EMN berbasis Family Cultural efektif terhadap peran petugas kesehatan dalam monitoring kesejahteraan janin di rumah (Tabel 3).

\section{PEMBAHASAN}

Selama di rumah, ibu hamil juga harus memiliki pengetahuan dan kemampuan dalam memenuhi kebutuhan nutrisi ibu dan janin, serta melakukan penilaian sederhana guna mengetahui kesejahteraan janin. Kemampuan ini dapat mendukung ibu hamil melalui fase kehamilan dengan kondisi ibu hamil dan janin sejahtera. Selain support keluarga, peran petugas kesehatan juga sangat penting dalam upaya preventif menurunkan kematian ibu dan janin melalui optimalisasi kompetensi ibu hamil untuk melakukan pengelolaan nutrisi selama masa kehamilan, juga kompetensi dalam mengenali janin sejahtera atau tidak selama ibu hamil di rumah (Gambar 1).

Model edukasi maternal neonatal (EMN) berbasis familyculture merupakan model edukasi melalui pelibatan keluarga sebagai support system utama bagi ibu hamil serta memperhatikan nilai-nilai budaya yang dianut oleh ibu dan keluarga mengenai nutrisi selama kehamilan. Dengan melibatkan keluarga dan memperhatikan nilai budaya yang dianut keluarga saat memberikan edukasi, model ini efektif dalam meningkatkan persepsi serta perilaku ibu dan keluarga 
mengenai nutrisi selama kehamilan dan dalam melakukan monitoring terhadap kesejahteraan janin.

Aplikasi model edukasi maternal berbasis family-culture dilakukan dengan cara memberikan edukasi pada ibu dan keluarga dengan memperhatikan budaya yang diyakini. Apabila budaya keluarga terkait nutrisi selama masa kehamilan serta dalam melakukan monitoring terhadap kesejahteraan janin sudah baik, maka petugas memberikan apresiasi yang positif pada ibu dan keluarga untuk melanjutkan perilaku hidup sehat dengan dukungan penuh dari keluarga. Sebaliknya, apabila persepsi serta budaya ibu dan keluarga kurang benar, maka dilakukan modifikasi dari aplikasi budaya tersebut agar budaya terkait nutrisi kehamilan masih bisa dianut namun tidak bertentangan dengan perilaku hidup sehat. Namun apabila budaya yang dianut ibu dan keluarga sudah menyimpang, maka dilakukan pembenaran dengan cara memberikan penjelasan melalui komunikasi yang baik, berdiskusi bersama anggota keluarga lainnya, dan mencari solusi agar budaya negatif tidak mempengaruhi nutrisi dan kesejahteraan janin.

Tabel 1. Data Demografi Ibu Hamil dengan Uji Statistik Deskriptif $(n=100)$

\begin{tabular}{lcc}
\hline Variabel & n & \% \\
\hline Usia & & \\
$\quad$ 20 tahun & 14 & 14.0 \\
$20-35$ tahun & 71 & 71.0 \\
$\quad>35$ tahun & 15 & 15.0 \\
Status Paritas & & \\
$\quad$ Primigravida & 36 & 36.0 \\
$\quad$ Multigravida & 59 & 59.0 \\
$\quad$ Grandemultigravida & 5 & 5.0 \\
Pendidikan & & \\
$\quad$ SD - SMP & 32 & 32.0 \\
$\quad$ SMA & 56 & 56.0 \\
$\quad$ Perguruan Tinggi & 12 & 12.0 \\
Pekerjaan & & 39.0 \\
$\quad$ Bekerja & 39 & 61.0 \\
$\quad$ Tidak Bekerja & 61 & 88.0 \\
Riwayat Antenatal Care & & 12.0 \\
$\quad$ Teratur & 88 & \\
$\quad$ Tidak Teratur & 12 & \\
\hline
\end{tabular}

Tabel 2. Peran Petugas Kesehatan dalam Optimalisasi Nutrisi Ibu Hamil Melalui Pendekatan Edukasi Maternal Neonatal (EMN) Berbasis Family-Cultural ( $\mathrm{n}=100)$

\begin{tabular}{|c|c|c|c|c|}
\hline Variabel & Mean & Std. Deviation & Std. Error Mean & P Value \\
\hline \multicolumn{5}{|c|}{ Persepsi Nutrisi Ibu hamil } \\
\hline Pretest & 60.51 & 3.372 & 0.823 & 0,01 \\
\hline Posttest & 78.30 & 5.283 & 1.084 & \\
\hline
\end{tabular}


Tabel 3. Peran Petugas Kesehatan Dalam Optimalisasi Monitoring Kesejahteraan Janin di Rumah Melalui Pendekatan Edukasi Maternal Neonatal (EMN) Berbasis Family-Cultural $(\mathrm{n}=100)$

\begin{tabular}{|c|c|c|c|c|}
\hline Variabel & Mean & Std. Deviation & Std. Error Mean & P Value \\
\hline \multicolumn{5}{|c|}{ Persepsi Monitoring Kesejahteraan Janin } \\
\hline Pretest & 51,60 & 4.116 & 0.736 & 0,03 \\
\hline Posttest & 75,65 & 5.214 & 0,934 & \\
\hline
\end{tabular}

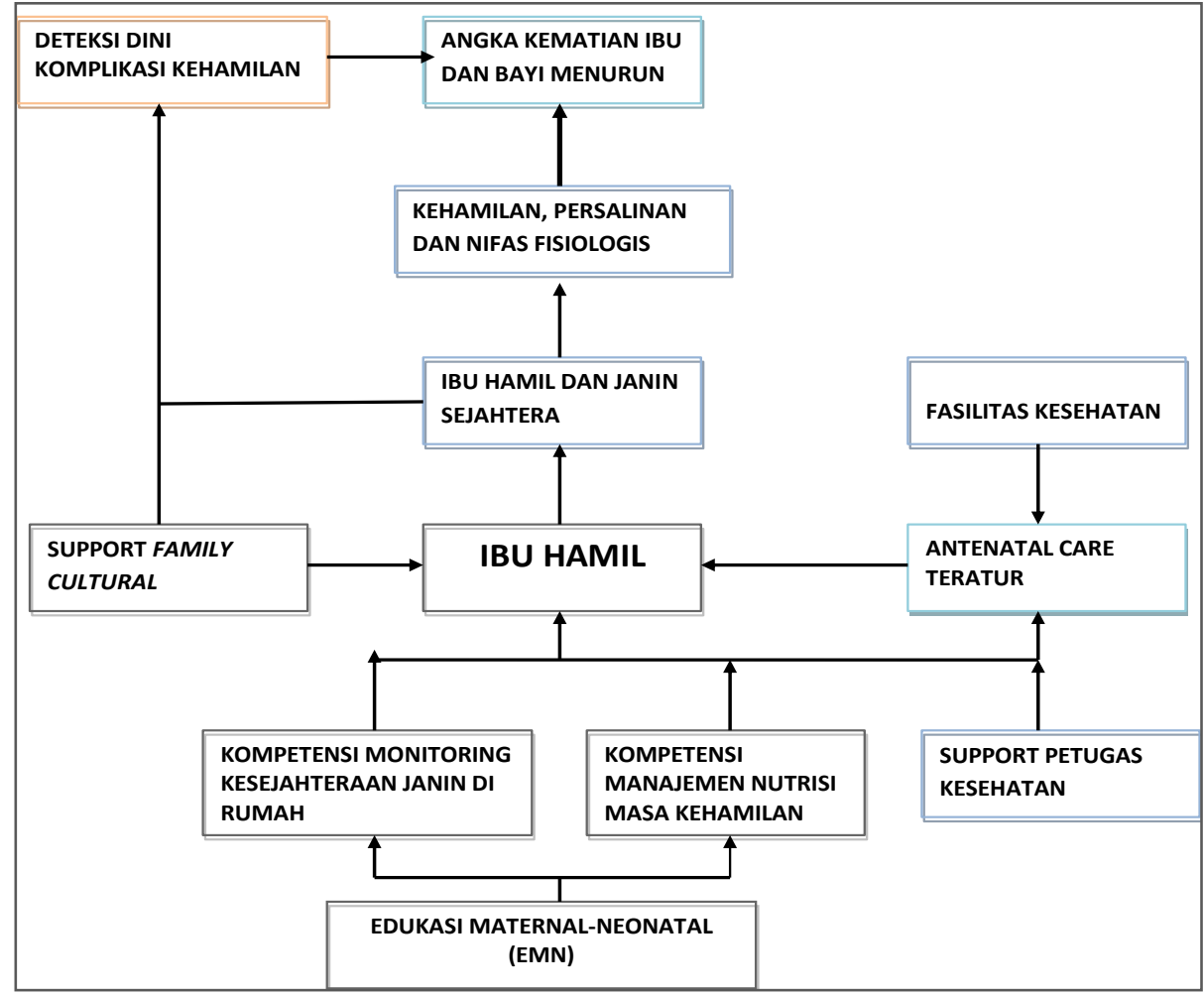

Gambar 1: Maternal-Neonatal (EMN) berbasis Family Cultural

Keterlibatan keluarga dalam diskusi sangat penting karena saling mempengaruhi satu sama lain. Hal ini sesuai teori Transkultural Leininger (2002) dalam Rejeki (2012) dikatakan bahwa terdapat 3 strategi yang dapat dilakukan dalam menyikapi budaya pasien, yaitu mempertahankan budaya dilakukan bila budaya pasien tidak bertentangan dengan kesehatan, negosiasi budaya dilakukan untuk membantu klien beradaptasi terhadap budaya tertentu yang lebih menguntungkan kesehatan dan restrukturisasi budaya dilakukan bila budaya yang dimiliki merugikan status kesehatan.

Selain keluarga petugas kesehatan merupakan pelaksana layanan kesehatan yang memiliki peranan sangat besar dalam mendukung kemampuan ibu dalam mengenal, memahami, dan mengubah perilaku ibu hamil untuk mengoptimalkan nutrisi selama menjalani kehamilan. Nutrisi sangat penting untuk menopang 
pertumbuhan janin dalam kehidupan intrauterin. Kecukupan nutrisi selama kehamilan sangat penting bagi ibu hamil dan janin karena dapat memberikan dampak yang besar. Beberapa penelitian telah membuktikan bahwa nutrisi selama kehamilan berhubungan erat dengan kejadian berat bayi lahir rendah (BBLR). Ibu hamil yang mengkonsumi kalori < 50\%, kenaikan berat bedan $\leq 4 \mathrm{~kg}$ selama kehamilan, berat badan $\leq 45 \mathrm{~kg}$ saat minggu terakhir kehamilan, tinggi $\leq$ $140 \mathrm{~cm}$, dan hemoglobin $<10$ $\mathrm{mg} /$ dlmempunyai faktor risiko BBLR (Metgud, Naik \& Mallapur, 2012). Terpenuhinya gizi janin berdampak perkembangan janin fisiologis, menurunkan komplikasi kehamilan seperti anemia, infeksi dalam kehamilan, pencegahan kejadian abortus dan lain-lain. Hal ini sejalan dengan penelitian yang dilakukan oleh Retni, Margawati dan Widjanarko (2016) yang mendapatkan hasil bahwa ibu hamil usia remaja dengan pertambahan berat badan yang kurang selama kehamilan KEK dan rendahnya asupan energi, protein, asam folat dan zat besi berisiko melahirkan bayi dengan BBLR. Mengingat peran petugas kesehatan membutuhkan kontinuitas peran secara terus menerus, maka petugas kesehatan dapat merencanakan kegiatan implementasi terkait edukasi nutrisi kehamilan lewat kegiatan antenatal care di Puskesmas, Posyandu maupun di Rumah sakit. Hal ini memiliki makna bahwa perlu adanya interaksi terus menerus antara ibu hamil dengan petugas kesehatan dalam rangka proses pemberian informasi kesehatan. Kondisi ini didukung oleh penelitian yang dilakukan oleh Handayani (2013) yang menguraikan tentang ibu hamil di Desa Sidomulyo, Sidokarto dan Sidoluhur memiliki kepatuhan dalam mengkonsumsi tablet besi lebih banyak yang baik. Peran petugas kesehatan dalam memotivasi ibu hamil untuk mengkonsumsi tablet besi mayoritas baik.

Selain kebutuhan nutrisi pada masa kehamilan, ibu hamil juga sangat penting untuk mengetahui pertumbuhan janin selama kehamilan. Tentu hal ini memerlukan kemampuan untuk melakukannya. Karena tidak mungkin ibu hamil setiap hari berinteraksi dengan petugas kesehatan dalam mengenali apakah janinnya sejahtera atau tidak, maka ibu hamil juga harus memiliki kemampuan untuk membuat kesimpulan tentang kesejahteraan janin. Berdasarkan kondisi ini sangat dibutuhkan peran petugas kesehatan mengedukasi ibu hamil untuk memiliki kompetensi monitoring kesejahteraan janin selama di rumah. Petugas kesehatan dapat mengajarkan sekaligus memberikan motivasi, bagaimana cara memonitor kesejahteraan janin secara sederhana selama ibu hamil di rumah di luar jadwal antenatal care di pelayanan kesehatan. Pentingnya edukasi petugas kesehatan ini didukung oleh penelitian yang dilakukan sebelumnya oleh Syamiyah dan Helda (2018) bahwa peluang kelompok ibu yang mendapatkan dukungan tenaga kesehatan dengan baik untuk memberikan ASI eksklusif adalah 1,6 (CI 95\% 1,022,34) kali dibandingkan dengan kelompok ibu yang kurang mendapatkan dukungan dari tenaga kesehatan. Disimpulkan bahwa Ibu yang mendapatkan 4 atau lebih dari 5 perlakuan diantaranya konseling ASI saat ANC, dilakukan IMD, dirawat 
gabung bersama bayi, bayinya tidak diberikan makanan dan minuman selain ASI selama masa perawatan, serta ibu pernah mendapatkan penyuluhan, maka peluangnya untuk memberikan ASI eksklusif lebih besar dibandingkan dengan ibu yang hanya mendapatkan 0-3 perlakuan tersebut.

Berdasarkan hal tersebut, maka peneliti dapat membuat kesimpulan bahwa dalam mempertahankan kesehatan ibu dan janin selain dukungan keluarga, dukungan petugas kesehatan sangat penting. Melalui peran etugas kesehatan ini, ibu dapat di diberikan informasi kesehatan salah satunya tentang nutrisi ibu hamil dan cara melakukan monitoring sederhana kesejahteraan janin selama ibu hamil di rumah.

\section{SIMPULAN}

Peran petugas kesehatan menggunakan pendekatan Model Edukasi Maternal-Neonatal (EMN) berbasis Family Cultural efektif dalam optimalisasi nutrisi ibu hamil dan monitoring kesejahteraan janin di rumah bagi ibu hamil di RSD Kalisat Jember dan Wilayah Puskesmas Sumbersari Jember.

$$
\text { Disarankan Petugas }
$$

Kesehatan menggunakan pendekatan Model Edukasi Maternal-Neonatal EMN), dalam rangka mengoptimalkan persepsi masyarakat dalam pemenuhan nutrisi ibu hamil dan pemantauan kesejahteraan janin selama ibu hamil di rumah. Petugas kesehatan juga bisa menggunakan media modul dalam proses aplikasi membangun persepsi masyarakat terkait nutrisi masa kehamilan dan monitoring kesejahteraan janin.

\section{DAFTAR PUSTAKA}

Anggraini, S.D., (2019). Dinkes Jatim: Semoga Tahun 2019 Angka Kematian Ibu dan Bayi Baru Lahir Menurun. https://www.timesindonesia.co. id/ Diakses 20 Juni 2020.

Baffour, T.D \& Chonody, J.M (2012). Do empowerment strategies facilitate knowledge and behavioral change?The impact of family health advocacyon health outcomes. Social Work in Public Health, 27:507-519.

DOI: 10.1080/19371918.2010.49499 1

Dinkes Kabupaten Jember, (2018). Survei Data Kesehatan AKI dan AKB di Kabupaten Jember. Dinkes Kab. Jember.

Fadlillah, N.G., (2019). Pernyataan Kebijakan Maternal Health. CIMSA. Empowering Medical Student Improving Nation's Health. https://cimsa.or.id/. Diakses 27 Juni 2020

Handayani, L. (2013). Peran Petugas Kesehatan Dan Kepatuhan Ibu Hamil Mengkonsumsi Tablet Besi. Kes Mas: Jurnal Fakultas Kesehatan Masyarakat, Universitas Ahmad Dahlan. Vol.7, No.2, September 2013, pp. $55 \sim 112$ ISSN: 1978-0575

Hanifah, L., (2009). Hubungan status gizi ibu hamil dengan berat badan lahir (studi kasus di RB Pokasi).https://digilib.uns.ac.id Higginbottom, G.M, Safipour. J, Mumtaz. Z, Chiu. Y, Paton. P \& Pillay, J. (2013). "I have to do what I believe": Sudanese women's beliefs and resistance to hegemonic practices at home and during experiences of maternity care in Canada. BMC 
Pregnancy and Childbirth. 13:51

Indriyani, D. (2013). Keperawatan

Maternitas Pada area

Perawatan Antenatal.

Yogyakarta: Graha Ilmu.

Indriyani, D., dan Asmuji. (2014).

Upaya Promotif dan Preventif

dalam menurunkan AKI dan

AKB. Yogyakarta: Arruz

Media.

Indriyani, D.Asmuji dan Wahyuni, S.

(2016). Edukasi Postnatal

dengan Pendekatan Family

Centered Maternity Care

(FCMC). Yogyakarta: Trans Medika

Jansen, L. (2010). The effect of maternal social support and religious commitment on prenatal health behaviors among Mexican-American women in North Central Texas. A Dissertation. UMI Number: 3446381

Kemenkes, (2016). Menkes Sampaikan Agenda SDGs Dalam Rakerkesnas 2016.http://www.depkes.go.id

Metgud C.S, Naik V.A \& Mallapur M.D. (2012). Effect of maternal nutrition on birth weight of newborn-A community based study. The Journal of Family Welfare. Vol. 58, No.2

Mundorf, C.A,Wilson, M.J, Shankar. A, Wickliffe, J.K, \&Lichtveld, M.Y. (2017). Cultural influences on the management of environmental health risks among low-income pregnant women. Health, Risk \& Society. Vol. 19, Nos. 7-8, 369-386,

https://doi.org/10.1080/136985

75.2017.1398819
Rejeki, S. (2012). Herbal dan Kesehatan Reproduksi Perempuan (Suatu Pendekatan Transkultural dalam Praktik Keperawatan Maternitas). Jurnal.unimus.ac.id. diakses 27 Juni 2020.

Retni., Margawati, A dan Widjanarko, B. (2016). Pengaruh Status Gizi \& Asupan Gizi Ibu Terhadap Berat Bayi Lahir Rendah Pada Kehamilan Usia Remaja . Jurnal Gizi Indonesia. ISSN : 1858-4942. Vol. 5, No. 1, Desember 2016 : 14-19.

Susiana, S. (2019). Angka Kematian Ibu: Faktor Penyebab Dan Upaya Penanganannya. Pusat Penelitian Badan Keahlian DPR RI. Vol. XI, No.24/II/Puslit/Desember/2019

Syamiyah, N dan Helda. (2018). Dukungan Tenaga Kesehatan Dalam Meningkatkan Pemberian ASI Eksklusif Ibu di Posyandu Wilayah Puskesmas Kecamatan Mampang Prapatan Jakarta. Jurnal Penelitian dan Pengembangan Pelayanan Kesehatan, Vol. 2, No. 1, April 2018

Varghese, R.P. (2009). Welfare consequences of coresiding with the mother-in-law in patriachal joint families for women and children: Evidence from India and Bangladesh. A Dissertation.

ProQuest

Dissertations \& Theses Global: The Humanities and Social Sciences Collection. UMI Number: 3362317 